\title{
Individual Essences in Avicenna’s Metaphysics
}

\author{
Muhammad Kamal \\ Asia Institute, The University of Melbourne, Melbourne, Australia \\ Email: muhammad@unimelb.edu.au
}

Received October $14^{\text {th }}$, 2013; revised November $14^{\text {th }}$, 2013; accepted November $21^{\text {st }}$, 2013

Copyright (C) 2014 Muhammad Kamal. This is an open access article distributed under the Creative Commons Attribution License, which permits unrestricted use, distribution, and reproduction in any medium, provided the original work is properly cited. In accordance of the Creative Commons Attribution License all Copyrights () 2014 are reserved for SCIRP and the owner of the intellectual property Muhammad Kamal. All Copyright (C) 2014 are guarded by law and by SCIRP as a guardian.

Central to Aristotle's metaphysics is the question of individuality. The individuality of each substance is explained in relation to "matter" because the "form" is universal. Avicenna, as one of the Aristotelian Neoplatonist philosophers, is not content with this explanation and proposes to establish individuality on other grounds. In this paper, I argue that in his perspective it is not the "matter" which determines individuality but rather the principle of existence.

Keywords: Essence; Existence; Form; Matter; Substance; Universal; Particular; Individual Essence; Necessary Existence; Possible Existents and Metaphysics

\section{Introduction}

Any inquiry into Aristotle's analysis of the principle of individuation is troubled by perplexity. On one side, Aristotle proposed that "essence" is what is universally shared by individual members of the same species. Individuals are different with respect to their features and shapes, but not with respect to their essence. Hence, "essence” is a principle of unity rather than individuality for members of that species. Consequently, it is difficult to establish individuation based on "essence". Aristotle and his followers searched for the principle of individuation somewhere else and concluded that it is the consequence of matter. Thus, two individuals are united in "essence", but their difference arises in relation to the corporeal aspect of their existence. On the other hand, Aristotle also refers to "essence" as individual existence.

If the position of Aristotle on the difference between individual corporeal substances is confusing, then how does Avicenna, as an Aristotelian-Neoplatonist philosopher, interpret the concept of individuation? Is his interpretation different from what Aristotle proposed? In this paper I examine Avicenna's principle of individuation and argue that although Avicenna belongs to the Aristotelian tradition in his approach to corporeal (hylomorphic) substances, nevertheless his principle of individuation may be viewed as based on an "essence-existence" dichotomy rather than on the distinction between form and matter.

\section{Aristotle’s Principle of Individuation}

Any discussion on individual essences will necessarily lead us back to Aristotle and in particular his concept of ousia, which is commonly translated as "substance". Although Aristotle deals with substance in a number of works, his analysis is provided mainly in the Categories and Book Z, of Metaphysics. In these two texts, Aristotle offers two criteria for deciding what things are substances. In the Categories substance, as the ultimate "subject", has ontological priority and all accidents are dependent for their existence on it. The subject is called the primary substance, such as particular human beings, horses, chairs etc. Genera and species, whose existence depends on the primary substances, are the secondary substances. The ultimate subject or the primary substance is also defined as that to which all other categories belong as predicates, whereas it is not predicated of anything. He writes: "Of things there are: (a) some are said of a subject but are not in any subject. For example, man is said of a subject, the individual man, but is not in any subject." (Aristotle, 1995a, 1b3-6; 5, 2a 34). The existence of accidents depends on the existence of the ultimate subject. Terence Irwin has described these two criteria as the subject-criterion and the essence-criterion. The former is a criterion by which everything other than the subject becomes a property of that subject and predicated of it. In the latter, when we try to know about something we can know it only by disclosing its essence. All non-substances are only known when they are related to a substance. Irwin also remarks that these two criteria will not frequently lead to different results (Irwin, 2002, 55).

Mary Louise Gill refers to the essence-criterion in terms of ontological priority. She also believes that Aristotle has provided a third criterion based on conceptual priority. This priority recognizes that a concept may be defined in terms of itself without reference to anything prior to $\mathrm{it}^{1}$. In his Metaphysics, Aristotle equates the subject-criterion with the ontological-criterion. This arrangement is grounded on the ontological priority of the ultimate subjects (the primary substances) as something that can be understood through itself without reference to anything else. For example, Socrates, as primary substance is on-

${ }^{1}$ Mary Louise Gill has also discussed Aristotle's notion of substance and the individual substances in an article published in the Journal of History of Philosophy. See: Mary Louise Gill (2005), “Aristotle’s Metaphysics Reconsidered”, in Journal of History of Philosophy, Vol. 143, No. 3. 
tologically prior to all accidents. The accident (i.e. being a philosopher) depends on Socrates' existence, but not the reverse. While Socrates continues to exist as a human being even after stripping him of this quality, being a philosopher does not inherently exist in the being of Socrates, but is accidentally attached to it (Aristotle, 1995b, 1029b, 13-22). Furthermore, Aristotle's reference to "said of a subject" and "in a subject" indicates the distinction between particulars and universals. Particulars are not said of any subject, whereas universals, which are either genera or species, are predicated of a subject (Irwin, 2002, 56). Primary substances, unlike non-substances, are persisting subjects and remain the same through time. In light of the stability of primary substances, Aristotle makes a distinction between two kinds of becoming. Firstly, the change in a nonsubstance does not bring about a new substance simply because a primary substance never changes and has no contrary. This kind of change in non-substances or accidents is called "qualified becoming”. For example, a "non-musical man” may become a "musical man", but he remains the same individual human being or primary substance. By contrast, in "unqualified becoming”, a new primary substance comes into existence through the process of generation and degeneration ${ }^{2}$.

Aristotle's definition of 'substance' in the Categories might not be difficult to understand. But in the Metaphysics, his views create some difficulty. Here Aristotle lists as substances not only the ultimate subject but also essence, universal and matter:

"The word 'substance' is applied, if not in more senses, still at least to four main objects; for both the essences and the universals and the genus are thought to be the substance of each thing, and fourthly the substratum. Now the substratum is that which other things are predicated, while it is itself not predicated of anything else.” (Aristotle, 1995b, 1028 b1, 35).

If essence is defined as a universal, such as a genus or a species, then essence becomes a substance of the second rank, because genera and species are secondary substances. If substance is the ultimate subject then matter will also be qualified for this position, as it is the persisting subject after being stripped of all forms attached to it. As we have mentioned, universals are secondary substances and common to all members of the same species: they are a (such), while a primary substance indicates a (this) or the existence of an individual entity. "If they are universal, they will not be substances; for everything that is common indicates not a 'this' but a 'such', but substance is a 'this'." (Aristotle, 1995b, 1003a10). But at another place, Aristotle insists that knowledge is possible through the universals. In this case, if particulars are substances then they will be unknowable. That is, our knowledge of the primary substances depends on the universals, which are predicated of them (Aristotle, 1995b, 1031a1, 5-10).

The essence-criterion helps us to think of essence as substance. The essence of an existing entity is a property that gives an identity to the entity and makes it persistent in different predications. Essence does not refer to all properties, rather it includes those which are essential and persist through time. In the previous example of a musical man, the property of 'musical' is not essential but accidental. It can easily be separated from 'an individual human' without affecting him or her. The property of 'musical', on the other hand, does not exist by itself without the

${ }^{2}$ The main reason for denying change in substance and accepting change only in the four categories of quantity, quality, position and space by Aristotle goes back to his idea that substance has no contrary. See: Aristotle, “Categories”, 4a 10-2, in Complete Works of Aristotle, Vol. 1. persisting subject. It has no essence of its own and remains as a predicate.

Aristotle vindicates the identification of essence with form. A meticulous study of his metaphysics reveals that forms produce individual substances when they are appended to matter. Form ("morphê") and matter (“hule") constitute the existence of every individual (corporeal) substance. Form and matter are different, but they are coexistent and inseparable in the world. They also represent the actual and potential aspects of the corporeal substances. Form is actuality and matter is potentiality (Aristotle, 1995b, 1045b, 9-10). With this analysis, Aristotle describes three kinds of substances: form, which is identified with essence, matter, and the corporeal substances. When applied to the criteria mentioned above, each criterion is qualified according to the position of its substance. Irwin remarks that proximate matter, which has a specific form, is more of a substance than remote matter because it is a basic subject. This, however, does not disqualify remote matter from becoming a substance. Remote matter may still be a substance, but not a primary substance (Irwin, 2002, 258). At another place, Aristotle stresses the significance of essence in dealing with individual substances. A bundle of universal determinations does not constitute substance in the sense of a single unified whole. For example, a pile of bricks do not represent a house. The materials become a house only when they attain the form of house. Similarly, a body is not Socrates unless the essence of Socrates dwells in it (Aristotle, 1995b, 1041b, 4-9). Matter has a twofold function; first, it fulfills the principle of individuation as members of a single species are distinguished not by their "essence" but by their material existence. Secondly, "matter" is a contributor with "essence" in the forming of composite substances.

The question, however, for us, is not to examine which of them is a substance, rather our aim is to investigate the principle of individuation. We seek to know what makes a substance (e.g. Socrates) an individual which is different from another individual substance of the same species. In this case, if we think of essence as a species-form, then Socrates and all other individual human beings participate in the same essence. At the same time, it is obvious that Socrates is an individual and different from other members of the human species. He has some essential properties peculiar to him which make him different from others. If form is universal and its contact with matter brings about individual substances, then individuality becomes accidental, and in this case it is "matter" rather than "form" which leads to the rise of individual substances: "And when we have the whole, such and such a form in this flesh and in these bones, this is Callias or Socrates; and they are different in virtue of their matter (for that is different), but the same in form; for their form is indivisible.” (Aristotle, 1995b, 1034a1, 5-10) Accordingly, the principle of individuation is established on "matter". Individuals of the same species are formally united and materially different. But still it is not clear how "matter" produces individual differences, or more specifically, how individuals may be identified as essentially different on the ground of their corporeality. The difference between two individuals, such as Callias and Socrates is not in their bodies (the material aspect of their existence), as they both possess bodies, but in the "shape" of those bodies. It should be remembered that our discussion is not focused on the physical difference between individuals. While individuals do have different physical shapes and features, it is not these physical differences which determine the individuality of their essences. Is it possible for the 
form to become the principle of individuation? Can we claim that two individual corporeal substances of the same species are different in form?

Searching for another entity beyond 'matter' to become the principle of individuation is far from meaningless because the idea that the difference between individual substances can be explained by their "matter" is not satisfactory. The importance of this search can also be supported by textual evidence where Aristotle refers to "form" as individual: "It follows, then, that substance has two senses, (a) the ultimate substratum, which is no longer predicated of anything else, and (b) that which is a 'this' and separable, and of this nature is the shape or form of each thing.” (Aristotle, 1995b, 1017b, 24-25) At another place Aristotle remarks, "The substratum is substance, and this is in one sense the matter (and by matter I mean that which, not being a "this" actually, is potentially a "this"), and in another sense the formula or form (which being a "this" can be separately formulated), and thirdly the complex of matter and form which alone is generated and destroyed, and is, without qualification capable of separate existence; for of substances in the sense of formulae some are separable and some are not." (Aristotle, 1995b). As we know, form is the principle of unity of individuals of the same species and as well as the unity of existence of an individual substance. This is based on the simple nature of form. Form does not lose its unity when it comes in contact with matter. For Aristotle, form is also universal and hence there will be no difference between one individual and another in regards to form. The essence of Socrates will be identical to the essence of Callias. On the other hand, it is stated that form is individual. If we think that substances retain their individuality after being separated from matter, then matter does not underlie the principle of individuation. But Aristotle believes in the existence of some separable substances. In this case, we need to turn to 'form' to determine the existence of individual substances. This is puzzling, but this second view of Aristotle can be seen as possible grounds for establishing the principle of individuation, and thinking about the difference between individual substances in terms of their essence rather than their physical shapes. Needless to say that what causes these individual substances to be individual is not easy to understand as Aristotle expresses conflicting views and provides no simple solution to the problem. After this analysis of Aristotle's position we proceed to interpret Avicenna's views on individual essences. This will necessarily require an understanding of his polarization of existence and his theory of an essence-existence distinction through which we will discuss the principle of individuation.

\section{Avicenna's Approach to the Question of Existence}

Avicenna follows Aristotle's distinction between substances and accidents but his metaphysics is characterized by the polarization of existence. All other problems, such as the distinction between form and matter, potentiality and actuality, and the one and the multiple are understood in light of this polarization. No doubt, one cannot deny Aristotle's influence on Avicenna; nonetheless he does not begin his philosophical thinking with a discussion on the principality of substance. The distinction between essence and existence and the ontological priority of each of them dominates his philosophy. On the grounds of this distinction, and the relationship between essence and existence, he identifies three metaphysical realms: necessary (wajib), possible (mumkin) and impossible (mumtani') ${ }^{3}$ (Avicenna, 2005, 30).

The reality of every existing entity depends on the relationship between essence and existence. This relationship, however, may be comprehended only when the distinction between these two aspects of an existing entity is made possible. In this triple division of existence a discussion on the relationship between essence and existence is thinkable only in the realm of the "possible". The "necessary" and the "impossible" are devoid of this relationship for different reasons. The former is existence without essence and the latter is essence without existence. The realm of the possible existing entities is located in the middle, between the realms of the necessary and the impossible and includes both essence and existence. Any entity which has the possibility of existence has an essence, which reveals itself in definition. If an existent entity has no essence, then it remains indefinable because definition is conceivable only when the universal determinations of the defined concept are known. As a consequence of this, only composite existents are definable.

Avicenna applies three criteria to justify his doctrine of polarization of existence. For the sake of clarification we call them: the causal, composable and truth criteria. Each realm of existence is computed by these criteria and in most cases, they have comparable outcomes. The causal criterion refers to the causal connection between existing entities. According to this criterion, the existence of anything that is not caused is necessary in itself, "That which in itself is a necessary existent has no cause, while that which in itself a possible existent has a cause. Whatever is a necessary existent in itself is a necessary existent in all its aspects." (Avicenna, 2005, 30). For an existent to become necessary in itself, it should be self-dependent. The non-existence of a prior cause for its existence is a primordial condition. In this manner its non-existence turns into impossibility. For this reason, the necessary existent cannot be known through a relationship with what is other than itself because it has no prior causal connection. If the necessary existent has a cause then this cause would be prior to its existence in time. Its existence, in this case, would not be necessary in itself (Avicenna, 2005, 38 and 1985, 262). Due to this distinctive characteristic of the necessary existent, Parviz Morewedge has described Avicenna's notion of the necessary existent as the most important feature of his philosophy. This notion also draws the line of demarcation between Avicenna's metaphysics and that of Aristotle and Plotinus (Morewedge, 1982, 313). It should be noted that Avicenna, unlike Aristotle, does not believe that God and the prime matter co-exist eternally. In his philosophy, the world, which is composite of essence and existence, emanates from God. In addition to this difference, Avicenna's metaphysical inquiry does not begin with substance and its relationship with accidents. Its major question is about "existence". This, however, does not mean that Avicenna disagrees with Aristotle on the definition of substance. He defines substance as the persisting subject of an accident (Avicenna, 2005, 45). On the other hand, his disagreement with Neoplatonism arises when the necessary existent is described as the ultimate reality and the first principle. In the emanationist doctrine of Plotinus the "One"

\footnotetext{
${ }^{3}$ Avicenna has also discussed these three regions of existence in: Avicenna (1985), Kitab al-Najat, Beirut: Dar Afaq al-Jadideh, part 3, the second essay See also Avicenna (1973), Danishnama-i 'ala'i, (The Book of Scientific Knowledge), translated by Parviz Morewedge, London: Routledge and Kegan Paul.
} 
is above "being" because "being" is divisible and many, whereas the "One" is absolute unity and simplex (Plotinus, 1953, 133). By contrast, for Avicenna nothing precedes the necessary existent. Otherwise, the necessary existent would not be the ultimate metaphysical principle.

On the other hand, whatever is produced by a cause is a possible existent and its non-existence is also a possibility: "Moreover, whatever is possible in existence when considered in itself, its existence and non-existence are both due to a cause. [This is] because, if it comes into existence, then existence, as distinct from nonexistence, would occurred to it. [Similarly] if it ceases to exist, then nonexistence would have occurred to it. Hence, in each of the two cases, what occurs to the thing must either occur through another or not. If [it occurs] through another, then [this] other is the cause. And if it did not exist through another, [then the nonexistence of the other is the cause of its nonexistence]" (Avicenna, 2005, 31). All existing entities, with the exception of the necessary existent, which is one in number for eternity, belong to the realm of the possible. Their existence is due to the necessary existent.

In explaining the second criterion, Avicenna states, "The existence of the Necessary Existent cannot be at all a composite, [deriving] from multiplicity. The true nature of the Necessary Existent can in no manner be shared by another. From our verifying [all] this, it follows necessarily that the Necessary Existent is not [dependent on] relation, is neither changing nor multiple, and has nothing associated with His existence that is proper to Himself.” (Avicenna, 2005). At another point in alShifa this view is re-affirmed by saying that "The First has no quiddity other than His individual existence.” (Avicenna, 2005, 274 , and 1985,265 ). The necessary existent is thus pure being and has no quiddity. This Avicennan view on the nature of the first principle is not inconsistent with that of Aristotle and Plotinus. For, whatever is composite presupposes its parts for its existence to be possible. Plotinus, for example, explained this principle in the Third Ennead. Dominic J. O’Meara refers to this as the "Principle of Prior Simplicity" (O’Meara, 1993, 44). Whatever is considered to be the first principle in the form of pure actuality or pure existence, it should be absolutely simple and not be shared by another. If the necessary existent is composite then it loses its principality. For this reason, its definition renders it impossible because it does not have quiddity, "the First also has no genus. This is because the First has no quiddity. That which has no quiddity has no genus, since genus is spoken of in answer to the question, "What is it?" and [moreover] genus in one respect is a part of a thing; and it has been ascertained that the First is not a composite.” (Avicenna, 2005, 277). The principality and the simple nature of the necessary existent are at the same time the denial of both a genus to which it belongs, and any unique differentia, otherwise it would be subsistent to a cause and thus a composite entity.

Possible existents are composite of essence and existence. It follows that no possible existents can become the first principle. Since no essence of the possible existents can become actually without existence in the world, they must be bestowed with "existence". This relationship between essence and existence as it refers to the possible existents is described in al-Shifa at two points. At one point Avicenna states that, "If [on the other hand] the existence of its quiddity is not sufficient [for specifying the possible with existence], [the latter] being, rather, something whose existence is added to it, then its existence would be necessarily due to some other thing.” (Avicenna, 2005, 31). And then in Book 8 of the same work, he writes, "It remains that the existence it has is due to a cause. Hence, everything that has a quiddity is caused. The rest of the things, other than the Necessary Existent, have quiddities. And it is these quiddities that in themselves are possible in existence, existence occurring to them externally.” (Avicenna, 2005, 276). This analysis is also related to the causal criterion because the existence of the possible existents is caused and becomes necessary only through the other and not through itself. This view, however, led to disputes among many scholars. Thinkers such as Abu Bakr Razi (864-925) and Ibn Rushd (1126-1198) believed that for Avicenna the existence of possible beings was an accident. Nassir alDin Tusi (1201-1274) arrived at a different interpretation. After rejecting the idea of the accidentality of existence in relation to possible existents, Tusi concluded that all essences, before coming into the world, existed in the mind of the Creator. As a consequence, essences cannot be detached from existence and we cannot say that existence is added to them. Whether a possible existent is in the mind of the Creator or actually in the world, it still has existence. In the first case, its existence is mental and in the second it is external. Fazlur Rahman, Seyyed Hossein Nasr and David Barrell also disagree with Razi and Ibn Rushd in that they don't accept the view that existence, according to Avicenna, is an accident. Barrell, for example, asserts that Avicenna's position is misinterpreted. He claims that this misinterpretation is the result of inaccuracies in the translation of his work into Latin (Burrell, 1993, 69; Nasr, 2006, 69; and Rahman, 1975, 27). Barrel's criticism is reasonable, but fails to recognize that Razi and Ibn Rushd read the works of Avicenna in the original language.

The third criterion is established on truth. For Avicenna, the necessary existent is permanently true. While the possible existents are not true in themselves but rely on the necessary existent for being true, "The Necessary Existent would thus be the permanently true in itself, while the possible existent would be true through another and false in itself. Hence, all things other than One Necessary Existent are, in themselves, false." (Avicenna, 2005, 38). The possible existents are not always true, and their truth is dependent on the status of their existence, which is granted by the necessary existent.

\section{Avicenna on Individual Essences}

The polarization of existence could become a parameter for understanding Avicenna’s individual essences. We know that, for this Muslim philosopher, there was only one necessary existent. But its oneness or singularity was not compatible with the individuality of a possible existent. The distinction between these two kinds of existence has already been examined through discussion of the three criteria mentioned above.

There is no doubt that the realm of the possible includes individual existents. Each of these existing entities is a composite of essence and existence. Its essence becomes actual through its existence. Hence, its possibility is dependent causally on 'existence'. We also know that existence is different from essence: "That whose existence is possible is preceded by the possibility of its existence and [the fact] that it is possible of existence." (Avicenna, 2005, 140). If we think of "essence" as something actual, like the form in Aristotle's metaphysics, then "existence" becomes a potentiality for essence. The potentiality of existence is the possibility of existence, making conditional even the corporeality of a substance. The possibility of an existent, whether 
it is corporeal or incorporeal, presupposes the potentiality of existence. The existence of something is thinkable only when it has potentiality of existence. This is a metaphysical prerequisite for "essence" to exist in the realm of the possible. The potentiality of existence may also be identified with "subject" or "hyle", but it is greater than any single physical and non-physical element, because it is a pre-existing ground for them.

The possible existent is an "essence" whose potentiality of existence is added to it externally. Its individuality, in the realm of the "possible", is explained through the potentiality of existence. Existence, in this context, becomes the principle for determining the possibility of essence to become an individual existent in the world. It is a particular mode of "existence" rather than a physical feature that transforms essence into an individual entity. Matter, for example, ascertains physical shape and features without resulting in essential differences between individuals. In this regards, the principle of existence is fundamental in Avicenna's metaphysics in order to distinguish between the necessary and the possible. The necessary existent is described as pure existence and the same principle provides the grounds for the realization of all individual essences in the realm of the "possible". In both the realms of the "necessary" and the "possible", existence is the principle of individuation. The necessary existent is one in kind, number and meaning. The possible essences, which are multiple, become individuals when "existence" is added to them, and they are transformed into composite substances.

Avicenna's position at this stage is new and different from that of Aristotle. The principle of existence draws the line between the metaphysical realms and gives rise to individual essences. But in Avicenna's analysis of the relation between form and matter, he follows Aristotle and relieves some confusion. After defining form as actuality, Avicenna attributes potentiality to matter. In this case, one can assert that 'matter' rather than 'existence' becomes the grounds for the rise of individual essences. Nevertheless this confusion can be evaded by referring to the potentiality of existence. In addition to this, matter is not an ontological condition for the existence of form, because form can exist without matter: "Form, therefore, is prior to matter; and it is not possible to say that form in itself always exists in potentiality, becoming actual only through matter. For actuality is the essence of form.” (Avicenna, 2005, 70). In Avicenna's doctrine of Hylomorphism the "existence" of a form transcends its association with matter. Matter does not cause the existence of the form. Its cause is "existence", which is bestowed on it by the necessary existent: "Form, then, exists only in hyle, [but] not in [the sense] that hyle is either the cause of its existence or of its existence in hyle. This is similar [to the way] in which cause exists only with effect, not in that the existence of the cause is [either] the effect or its being with the effect." (Avicenna, 2005). It is not "matter" that causes the form to exist in the realm of the possible because the necessary existence is the originator of form, matter and their association with one another. The potentiality of existence precedes everything in the realm of the possible. It even becomes a pre-condition for matter to be in the world. Avicenna also recognizes the existence of incorporeal individual essences. As a consequence, matter could not be considered the principle of individuation, otherwise how could an incorporeal individual essence exist? And, then, in explaining the relationship between actuality and potentiality he remarks that: "For potency in [these particular things], precedes the act in terms of temporal precedence. As regards universal things or eternal non-corruptible things, even though [they be] particulars, whatever is in potency never precedes them at all. Moreover, after [taking into account] these conditions, potency is posterior in all respects. This is because, inasmuch as potency does not subsist in itself, it must subsist in a substance that needs to be in act.” (Avicenna, 2005, 141). The eternal non-corruptible things are incorporeal individual essences. These essences are pure forms or actuality and exist without depending on matter. Their actual existence in individual forms precedes their association with matter. If we think of "matter" as potentiality then the individual incorporeal essences do not rely on matter to become individual existents because potentiality is posterior to them. Their existence, even in the realm of the possible, is due to the potentiality of their existence.

Avicenna re-examines the status of individual essences in Book Five of al-Shifa and accepts the existence of individual souls with a number of universal determinations. For him, the individual soul does not have a single universal form, rather, each soul possesses a particular nature. We understand that individual souls are associated with matter in the realm of the possible; but here their individuality is defined in terms of this particular nature rather than any physical characteristic: “As regards its being with matter and accidents and this individual - even though the providence of God's, exalted be He, it is due to the particular nature.” (Avicenna, 2005, 156). An individual might be different in physical features and accidents from another individual, but their essential difference is not dictated by the body. It is due to their particular nature. Avicenna also asserts the impossibility of a universal form to be numerically one, predicated of many and identical with each of them. In this sense, the particular nature cannot be both universal and part of a concrete possible existent at the same time. Universal determination is a mental conception. If we think of "humanity", for example, as the particular nature of an individual human being, then it should exist numerically because the nature of one individual is not identical with the nature of another individual. It is worth mentioning that the particular nature is not something material. Avicenna argues against Antiphon who identified nature with matter, because the particular nature provides substantiality and continues to exist without matter (Avicenna, 2009, 48).

No doubt, Avicenna does not deny the prospect of accidental differences among the possible existents. The accidental differences appear when the essence of a possible existent is found in conjunction with matter: "Its existence would thus have been affiliating external accidents and states with it, through which it is individuated." (Avicenna, 2005, 158). Accidental differences may be physical as well as non-physical qualities, by which an individual existent is identified. But, it should be noted that the accidental qualities are not essential to the existence of an individual entity: "No one with a sound temperament can rationally perceive that one humanity is embraced by accidents of 'Amr and that is very same [humanity] has embraced the accidents of Zayd.” (Avicenna, 2005, 159). Since individuality is real it cannot be warranted by universals. The universals are intellectual and have no reality outside the domain of thinking. The possible existents are not subsistent to them. However, Avicenna believes in the unitary nature of individual essences. For him, each essence is a single entity, but its individuality is beyond the aggregation of the accidents and universals. This relation between the individual essence and the accidents is not comparable with the relation between the whole and the parts. The 
whole is identical to the sum of its parts and does not exist without them. The individual essence of the possible existents is not dependent on accidents. The accidents, on the other hand, do not constitute the nature of the individual essence. The particular nature, which is identical to the individual essence, is different from a unified and integrated group of accidents and universals, If this was not so, its individuality would remain determined by the co-presence of them rather than the singularity of its own existence: "Hence, there must be many relations to an essence that is numerically one. And the numerically one essence, inasmuch as it is so, is numerically individual. The soul itself also conceives another universal that combines this form and another in this soul or in another soul. For, all these, inasmuch as they are in the soul, are defined by one definition.” (Avicenna, 2005). Based on this relation between the individual essence, which is numerically one, and the accidents there is a clear distinction between the possible existents and the accidents or universals predicated of them. Since the individual essence has its own existence, the participation of the accidents should not affect it.

The existence of the individual essence as an independent reality requires a different type of relationship with its accidents, which is necessary and contingent at the same time. It is necessary as no accident can exist without an individual essence and contingent because the individual essence does not depend on accidents for its existence. Accordingly, accidents and universals do not cause the individual essence. Through this relation the accidents are present only when there is an individual essence. The existence of an individual essence is not the result of accidents and universals but rather of itself because it is prior to them. This priority resembles the priority between something simple and complex.

\section{Conclusion}

In the end it is important to understand that the distinctiveness of Avicenna's attempt to found a ground for individuality can be demonstrated in light of his interpretation of the relationship between essence and existence. Unlike Aristotle, Avicenna does not rely on a particular aspect or one part of the possible existents, such as the "matter" or the "form". The individuality of each essence is found on its "existence". Avicenna also introduces the notion of the "particular nature", which exists prior to all accidents and universals. This particular nature is identified with the individual essence and becomes a unity which transcends the plurality of the accidents and the universals. Consequently, the individual essence is not an aggregation of parts but a single entity which has its own unique mode of existence.

\section{REFERENCES}

Aristotle (1995a). Categories. In J. Barnes (Ed.), Complete works of Aristotle, Vol. 1. Princeton, New Jersey: Princeton University Press.

Aristotle (1995b). Metaphysics. In J. Barnes (Ed.), Complete works of Aristotle, Vol. 2. Princeton, New Jersey: Princeton University Press.

Aristotle (1995c). Physics. In J. Barnes (Ed.), Complete works of Aristotle, Vol. 1. Princeton, New Jersey: Princeton University Press.

Aristotle (1995d). De Generatione et Corruptione. In J. Barnes (Ed.), Complete works of Aristotle, Vol. 1. Princeton, New Jersey: Princeton University Press.

Avicenna (1985). Kitab al-Najat, Beirut: Dar Afaq al-Jadideh.

Avicenna (1973). Danishnama-i 'ala'i, (The Book of Scientific Knowledge), translated by Parviz Morewedge. London: Routledge and Kegan Paul.

Avicenna (2005). The metaphysics of healing (al-Shifa), a parallel English-Arabic text, translated, introduced and annotated by Michael Marmura. Provo, Utah: Brigham University Press.

Avicenna (2009). The physics of the healing, Books I \& II, a parallel English-Arabic text, translated, introduced and annotated by Jon McGinnis. Provo, Utah: Brigham Young University Press.

Burrell, D. B. (1993). Aquinas and Islamic and Jewish thinkers. In N. Kretzmann, \& E. Stump (Eds.), The Cambridge companion to aquinas. Cambridge: Cambridge University Press. http://dx.doi.org/10.1017/CCOL0521431956.004

Gill, M. L. (1991). Aristotle on substance: The paradox of unity. Princeton, NJ: Princeton University Press.

Irwin, T. H. (2002). Aristotle's first principles. Oxford: Clarendon Press.

Morewedge, P. (1982). Philosophies of existence ancient and medieval. Parviz Morewedge, New York: Fordham University Press.

Nasr, S. H. (2006). Islamic philosophy from its origin to the present: Philosophy in the land of prophecy. Albany: State University Press of New York Press.

O’Meara, D. J. (1993). Plotinus: An introduction to enneads. Oxford: Clarendon Press.

Plotinus (1952). The six enneads. Translated by Stephen MacKenna and B. S. Page, Chicago, London, Toronto: William Benton Publisher.

Rahman, F. (1975). The philosophy of Mulla Sadra (Sadr al-Din al-Shirazi). Albany: State University of New York Press. 